\title{
ANALISIS FAKTOR YANG MEMPENGARUHI SELF AWARENESS MASYARAKAT DALAM MELAKUKAN MITIGASI BENCANA DI AREA RAWAN BENCANA GUNUNG BROMO DESA NGADISARI, KECAMATAN SUKAPURA - PROBOLINGGO
}

\author{
Achmad Kusyairi ${ }^{1)}$, Widya Addiarto ${ }^{2)}$ \\ Nursing Program, Institute of Health Science Hafshawaty Pesantren Zainul Hasan \\ email : kusyerachmad@gmail.com
}

\begin{abstract}
Abstrak
Gunung meletus menjadi bahaya karena dapat merugikan secara fisik maupun non fisik dan korban yang tidak sedikit. Kesadaran diri masyarakat (self awareness) menjadi sikap yang sangat dibutuhkan untuk membangun masyarakat yang tangguh dan peka terhadap bencana. Tujuan dari penelitian ini adalah mengetahui faktor yang paling dominan berhubungn dengan self awareness masyarakat dalammelakukan mitigasi bencana. Penelitian ini menggunakan metode deskriptif analitik dengan pendekatan cross sectional. Populasi dalam penelitian ini adalah 673 dan sampel yang diambil adalah 250 responden. Data dikumpulkan menggunakan kuesioner. Hasil analisis multivariat menggunakan uji regresi logistik didapatkan bahwa faktor yang paling berhubungan dengan awareness adalah pendapatan $(O R=0.351)$, usia $(O R=0.268)$ dan pendidikan $(O R=0.044)$. Oleh karena itu, semakin besar pendapatan masyarakat akan berpengaruh terhadap self awareness masyarakat dikarenakan akan meningkatkan kesiapsiagaan dan usaha dalam mencegah resiko bencana yang lebih besar melalui mitigasi bencana yang lebih baik.
\end{abstract}

Kata Kunci : self awareness, mitigasi, bencana

\begin{abstract}
Mount erupt becomes a danger because it can harm both physically and non physically and the victims are not minimum. Self awareness becomes an indispensable attitude to building a community that is resilient and sensitive to disaster. The purpose of this study is to determine the factors that most influence the self awareness of the community in conducting disaster mitigation. This research uses descriptive analytic design between variables with cross sectional approach. Population and sample in this research are All Population in Dusun Cemaralawang, Desa Ngadisari, Kec.Sukapura, Probolinggo A total of 673 with sampe simpe random technique, so get 250 respondents. Data collection using questionnaire. Based on the results of multivariate test, it can be seen that from 4 categories of factors that meet the criteria of logistic regression test, the factors that most influence self awareness from the biggest to the smallest is income factor with the strength of relationship $(O R=0.351)$, age $(O R=0.268)$ and education $(O R=0.044)$. Therefore, people with large incomes will have better preparation than people with low incomes. This is because with a large income they can use the funds they have for disaster mitigation efforts or in other words prevent the occurrence of disasters by doing good development. Thus the risk of disaster can be minimized.
\end{abstract}

Keywords: self awareness, mitigation, disaster

\section{PENDAHULUAN}

Gunung meletus atau merapi menjadi bahaya karena dapat merugikan secara fisik maupun non fisik dan korban yang tidak sedikit (Feldman \& Tilling, 2012). Dampak bencana muncul ketika ancaman gunung api bertemu dengan masyarakat yang rentan di perkampungan di lereng gunung api yang tidak mempunyai kesadaran (awareness) dalam mempersiapkan kewaspadaan menanggapi terhadap ancaman bencana tersebut (Elazeem, Adam \& Gehan, 2011). Oleh karena itu, perlu adanya persiapan atau management bencana gunung berapi untuk mengurangi terjadinya korban jiwa dan kerugian harta dan benda (Burke et al., 2011).

Kesadaran diri masyarakat (self awareness) 
menjadi sikap yang sangat dibutuhkan untuk membangun masyarakat yang tangguh dan peka terhadap bencana. Akan tetapi, kenyataan yang ditemui di lapangan adalah minimnya kesadaran diri (self awareness) dari masyarakat, sehingga bencana yang terjadi sewaktu-waktu dapat menimbulkan dampak yang sangat besar bagi lingkungan sekitar (Putra, 2011). Self awarenessdipengaruhi oleh beberapa faktor diantaranya kebudayaan, pendidikan, gender dan pengalaman sebelumnya (Burke, 2011).

Hasil studi pendahuluan yang telah dilakukan pada bulan Oktober 2017 di Desa Ngadisari Kecamatan Sukapura didapatkan data bahwa desa tersebut merupakan area paling dekat dengan kawasan rawan bencana pegunungan Bromo Tengger, Probolinggo. Pada tahun 2014 gunung Bromo sempat berstatus Awas selama 1 bulan, hampir sebagian besar masyarakat $90 \%$ di desa Ngadisari mengungsi ke kota untuk menghindari korban bencana yang bertambah. Kondisi saat ini, tingkat kesadaran masyarakatnya masih sekitar 55\%, tergolong rendah untuk kawasan paling rentan terhadap ancaman bencana. Hasil wawancara juga menunjukkan bahwa sebagian besar peduduknya belum banyak dilibatkan dalam mitigasi bencana oleh pemerintah setempat. Selain itu, upaya pendidikan tentang manajemen bencana masih sangat jarang dan terbatas dilakukan oleh petugas setempat.

Tujuan untuk mengetahui faktor-faktor yang paling dominan (faktor pendapatan, ras/suku, jenis kelamin, kepemilikan, usia, pendidikan dan pengalaman) berhubungan dengan self awareness masyarakat dalam melaksanakan mitigasi bencana di area rawan bencana gunung Bromo.

\section{METODE PENELITIAN}

Penelitian ini menggunakan desain penelitian pre deskriptif analitik antar variabel dengan pendekatan cross sectional. Populasi dan sampel dalam penelitian ini adalah Semua Penduduk di Dusun Cemaralawang, Desa Ngadisari, Kec.Sukapura, Probolinggo Sejumlah 673 dengan teknik sampling simpe random, maka di dapatkan responden sebanyak 250. Pengumpulan data menggunakan kuesioner. Untuk mengetahui perbedaan factor yang dominan maka digunakan uji statistik bivariate chi square dan regresik logistic untuk uji multivariatnya dengan tingkat signifikansi $\leq 0,05$.

\section{HASIL DAN PEMBAHASAN}

\section{Gambaran Umum Tempat Penelitian}

Penelitian ini akan dilaksanakan di Desa Ngadisari, Kecamatan Sukapura Kabupaten Probolinggo.

\section{Gambaran Karakteristik Responden}

Tabel 1. Gambaran Karakteristik Responden Berdasarkan Jenis Kelamin

\begin{tabular}{|c|c|c|}
\hline $\begin{array}{c}\text { Jenis } \\
\text { Kelamin }\end{array}$ & $\begin{array}{l}\text { Frekuensi } \\
\text { (f) }\end{array}$ & $\begin{array}{c}\text { Persentase } \\
(\%)\end{array}$ \\
\hline Laki-laki & 145 & 58 \\
\hline Perempuan & 105 & 42 \\
\hline TOTAL & 250 & 100 \\
\hline
\end{tabular}

Pada tabel 1, diketahui responden pada penelitian ini mayoritas adalah laki-laki sebanyak 145 orang (58\%) sedangkan responden perempuan sebanyak 105 orang $(42 \%)$.

Tabel 2. Gambaran Karakteristik Responden Berdasarkan Usia

\begin{tabular}{lcc}
\hline \multicolumn{1}{c}{ Usia } & $\begin{array}{c}\text { Frekuensi } \\
(\mathbf{f})\end{array}$ & $\begin{array}{c}\text { Persentase } \\
(\boldsymbol{\%})\end{array}$ \\
\hline Remaja & 104 & 42 \\
Dewasa & 146 & 58 \\
\hline TOTAL & 250 & 100 \\
\hline
\end{tabular}

Pada tabel 2, diketahui responden pada penelitian ini mayoritas adalah usia dewasa sebanyak 146 orang (58\%) sedangkan responden dengan usia remaja sebanyak 104 orang $(42 \%)$.

Tabel 3. Gambaran Karakteristik Responden Berdasarkan Tingkat Pendidikan

\begin{tabular}{lcc}
\hline Pendidikan & $\begin{array}{c}\text { Frekuensi } \\
(\mathbf{f})\end{array}$ & $\begin{array}{c}\text { Persentase } \\
(\boldsymbol{\%})\end{array}$ \\
\hline Menengah & 172 & 69 \\
Tinggi & 78 & 31 \\
\hline TOTAL & 250 & 100 \\
\hline
\end{tabular}

Pada tabel 3, diketahui responden pada penelitian ini mayoritas adalah pendidikan menengah sebanyak 172 orang (69\%) sedangkan responden dengan pendidikan tinggi sebanyak 78 orang $(31 \%)$. 
Tabel 4. Gambaran Karakteristik Responden Berdasarkan Pengalaman Telibat Mitigasi

\begin{tabular}{lcc}
\hline $\begin{array}{c}\text { Pengalaman terlibat } \\
\text { Mitigasi }\end{array}$ & $\begin{array}{c}\text { Frekuensi } \\
(\mathbf{f})\end{array}$ & $\begin{array}{c}\text { Persentase } \\
(\boldsymbol{\%})\end{array}$ \\
\hline Ada Pengalaman & 180 & 72 \\
Tidak ada pengalaman & 70 & 28 \\
\hline TOTAL & 250 & 100 \\
\hline
\end{tabular}

Pada tabel 4, diketahui responden pada penelitian ini mayoritas adalah mempunyai pengalaman sebelumnya sebanyak 180 orang $(72 \%)$ sedangkan responden dengan tanpa pengalaman sebanyak 70 orang $(28 \%)$.

Tabel 5. Gambaran Karakteristik Responden Berdasarkan Suku atau Ras

\begin{tabular}{lcc}
\hline \multicolumn{1}{c}{ Suku/Ras } & $\begin{array}{c}\text { Frekuensi } \\
(\mathbf{f})\end{array}$ & $\begin{array}{c}\text { Persentase } \\
(\boldsymbol{\%})\end{array}$ \\
\hline Jawa & 115 & 46 \\
Non Jawa & 135 & 54 \\
\hline \multicolumn{1}{c}{ TOTAL } & 250 & 100 \\
\hline
\end{tabular}

Pada tabel 5, diketahui responden pada penelitian ini mayoritas adalah suku non Jawa sebanyak 135 orang (54\%) sedangkan responden dengan tanpa pengalaman sebanyak 115 orang $(46 \%)$.

Tabel 6. Gambaran Karakteristik Responden Berdasarkan Pendapatan

\begin{tabular}{lcc}
\hline Pendapatan & $\begin{array}{c}\text { Frekuensi } \\
(\mathbf{f})\end{array}$ & $\begin{array}{c}\text { Persentase } \\
(\boldsymbol{\%})\end{array}$ \\
\hline UMR & 160 & 64 \\
$>$ UMR & 90 & 36 \\
\hline \multicolumn{1}{c}{ TOTAL } & 250 & 100 \\
\hline
\end{tabular}

Pada tabel 6, diketahui responden pada penelitian ini mayoritas adalah pendapatan sesuai UMR sebanyak 160 orang (64\%) sedangkan responden dengan pendapatan lebih dari UMR sebanyak 90 orang (36\%).

Tabel 7. Gambaran Karakteristik Responden Berdasarkan Tingkat Self-Awareness Responden

\begin{tabular}{lcc}
\hline Self Awareness & $\begin{array}{c}\text { Frekuensi } \\
(\mathbf{f})\end{array}$ & $\begin{array}{c}\text { Persentase } \\
(\boldsymbol{\%})\end{array}$ \\
\hline Baik & 83 & 33 \\
Kurang Baik & 167 & 67 \\
\hline TOTAL & 250 & 100 \\
\hline
\end{tabular}

Pada tabel 7, diketahui tingkat self awareness responden pada penelitian ini mayoritas adalah kurang baik, yaitu sebanyak 167 orang (67\%) sedangkan responden dengan self awareness baik adalah sebanyak 83 orang (33\%).

\section{Data Khusus Penelitian (Analisis Bivariat)}

Tabel 8. Hasil Uji Bivariat Chi Square Hubungan Jenis Kelamain dengan Self Awareness Responden

\begin{tabular}{lccc}
\hline \multirow{2}{*}{$\begin{array}{c}\text { Jenis } \\
\text { Kelamin }\end{array}$} & \multicolumn{2}{c}{ Self Awareness } & p value \\
\cline { 2 - 3 } & Baik & $\begin{array}{c}\text { Kurang } \\
\text { Baik }\end{array}$ & \\
\hline Laki-laki & 40 & 105 & \\
Perempuan & 43 & 62 & 0,027 \\
\hline \multicolumn{1}{c}{ TOTAL } & 83 & 167 & \\
\hline
\end{tabular}

Berdasarkan tabel uji silang (tabel 8), terdapat hubungan yang signifikan antara faktor karakteristik responden yaitu jenis kelamin dengan self awareness responden dengan nilai $\boldsymbol{\rho}$ value 0,027 ( $\rho$ value $<0,05)$.

\section{Hubungan Usia dengan Self Awareness Responden}

Tabel 9. Hasil Uji Bivariat Chi Square Hubungan Usia dengan Self Awareness Responden

\begin{tabular}{lccc}
\hline \multirow{2}{*}{ Usia } & \multicolumn{2}{c}{ Self Awareness } & \\
\cline { 2 - 3 } & Baik & $\begin{array}{c}\text { Kurang } \\
\text { Baik }\end{array}$ & \\
\hline Remaja & 22 & 82 & \\
Dewasa & 61 & 85 & 0,001 \\
\hline TOTAL & 83 & 167 & \\
\hline
\end{tabular}

Berdasarkan tabel uji silang (tabel 9), terdapat hubungan yang signifikan antara faktor karakteristik responden yaitu usia dengan self awareness responden dengan nilai $\rho$ value $0,001$ ( $\rho$ value $<0,05)$.

\section{Hubungan Pendidikan dengan Self Awareness Responden}

Tabel 10. Hasil Uji Bivariat Chi Square Hubungan Pendidikan dengan Self Awareness Responden

\begin{tabular}{lccc}
\hline \multirow{1}{*}{ Pendidikan } & \multicolumn{2}{c}{$\begin{array}{c}\text { Self } \\
\text { Awareness }\end{array}$} & $\begin{array}{c}\boldsymbol{\rho} \\
\text { value }\end{array}$ \\
\cline { 2 - 3 } & Baik & $\begin{array}{c}\text { Kurang } \\
\text { Baik }\end{array}$ & \\
\hline Pendidikan Menengah & 22 & 150 & \\
Pendidikan Tinggi & 61 & 17 & 0,000 \\
\hline TOTAL & 83 & 167 & \\
\hline
\end{tabular}


Berdasarkan tabel uji silang (tabel 10), terdapat hubungan yang signifikan antara faktor karakteristik responden yaitu pendidikan dengan self awareness responden dengan nilai $\rho$ value $\mathbf{0 , 0 0 0}(\rho$ value $<0,05)$.

Hubungan Pengalaman Mitigasi dengan Self Awareness Responden

Tabel 11. Hasil Uji Bivariat Chi Square Hubungan Pengalaman Mitigasi dengan Self Awareness Responden

\begin{tabular}{|c|c|c|c|}
\hline \multirow[b]{2}{*}{ Pengalaman Mitigasi } & \multicolumn{2}{|c|}{ Self Awareness } & \multirow{2}{*}{$\begin{array}{c}\rho \\
\text { value }\end{array}$} \\
\hline & Baik & $\begin{array}{c}\text { Kurang } \\
\text { Baik }\end{array}$ & \\
\hline Ada Pengalaman & 56 & 124 & \multirow{3}{*}{0,0261} \\
\hline Tidak AdaPengalaman & 27 & 43 & \\
\hline TOTAL & 83 & 167 & \\
\hline
\end{tabular}

Berdasarkan tabel uji silang (tabel 11), tidak terdapat hubungan yang signifikan antara faktor karakteristik responden yaitu pengalaman dengan self awareness responden dengan nilai $\rho$ value $0,261$ ( $\rho$ value $>0,05)$

\section{Hubungan Suku/Ras dengan Self Awareness Responden}

Tabel 12. Hasil Uji Bivariat Chi Square Hubungan Suku/Ras dengan Self Awareness Responden

\begin{tabular}{lccc}
\hline \multirow{2}{*}{ Suku/Ras } & \multicolumn{2}{c}{ Self Awareness } & \\
\cline { 2 - 3 } & Baik & $\begin{array}{c}\text { Kurang } \\
\text { Baik }\end{array}$ & p value \\
\hline Jawa & 42 & 73 & \\
Non Jawa & 41 & 94 & 0,303 \\
\hline TOTAL & 83 & 167 & \\
\hline
\end{tabular}

Berdasarkan tabel uji silang (tabel 12), tidak terdapat hubungan yang signifikan antara faktor karakteristik responden yaitu suku/ras dengan self awareness responden dengan nilai $\rho$ value $\mathbf{0 , 3 0 3}$ ( $\rho$ value $>0,05$ )

\section{Hubungan Pendapatan dengan Self Awareness Responden}

Tabel 13. Hasil Uji Bivariat Chi Square Hubungan Pendapatan dengan Self Awareness Responden

\begin{tabular}{|c|c|c|c|}
\hline \multirow[b]{2}{*}{ Pendapatan } & \multicolumn{2}{|c|}{ Self Awareness } & \multirow{2}{*}{$\rho$ value } \\
\hline & Baik & $\begin{array}{c}\text { Kurang } \\
\text { Baik }\end{array}$ & \\
\hline UMR & 27 & 133 & 0,000 \\
\hline$>\mathrm{UMR}$ & 56 & 34 & \\
\hline TOTAL & 83 & 167 & \\
\hline
\end{tabular}

Berdasarkan tabel uji silang (tabel 13), terdapat hubungan yang signifikan antara faktor karakteristik responden yaitu pendapatan dengan self awareness responden dengan nilai $\rho$ value $0,000$ ( $\rho$ value $<0,05)$.

Berdasarkan hasil uji bivariat dari masingmasing faktor karakteristik yang memenuhi syarat uji multivariat adalah variabel yang memiliki nilai $\mathrm{p}<0,25$ pada hasil uji analisis bivariat. Oleh karena itu, variabel yang memenuhi syarat tersebut adalah jenis kelamin $(\mathrm{p}=0,027)$, usia $(\mathrm{p}=0,001)$, pendidikan $(\mathrm{p}=0,000)$ dan pendapatan $(\mathrm{p}=0000)$. Analisis multivariat yang diguakan adalah uji regresi logistik karena variabel dependen pada penelitian ini memiliki skala kategorik.

Berdasarkan hasil uji multivariat, dapat diketahui bahwa dari 4 kategori faktor yang memenuhi kriteria uji regresi logistik, faktor yang paling mempengaruhi self awareness dari yang terbesar ke yang terkecil adalah faktor pendapatan dengan kekuatan hubungan $(\mathrm{OR}=0,351)$, usia $(\mathrm{OR}=0,268)$ dan pendidikan $(\mathrm{OR}=0,044)$.

\section{PEMBAHASAN}

Berdasarkan data hasil penelitian, didapatkan bahwa ada hubungan yang signifikan antara faktor karakteristik responden yaitu jenis kelamin dengan Self Awareness responden dengan nilai $\rho$ value 0,027 ( $\rho$ value $<0,05$ ). Hal ini sesuai dengan Mollahosseini (2011) bahwa adanya perbedaan jenis kelamin akan memberikan dampak terhadap kesiapsiagaan dan kesadaran diri dalam bencana. Hal ini berhubungan erat dengan perilaku laki-laki akan memiliki rasa kesiapsiagaan yang lebih tinggi dibandingkan perempuan. Akan tetapi hal ini berbanding terbalik dengan pernyataan Austin (2010) bahwa wanita juga memiliki responsibilitas yang cukup baikdalam merespon bencana.

Sedangkan pada hasil lainnya berdasarkan tabel uji silang (tabel 9), terdapat hubungan yang signifikan antara faktor karakteristik responden yaitu usia dengan self awareness responden dengan nilai $\rho$ value 0,001 ( $\rho$ value $<0,05$ ). Menurut Pajooh, Mohammad dan Abdul (2014) menyatakan bahwa semakin bertambah usia makan kesiapsiagaan akan mengalami penurunan. Dari dewasa sampai lansia akan mengalami penurunan kesiapsiagaan. Usia remaja sampai dewasa muda merupakan puncak kesiapsiagaan. Hal ini dikarenakan kelompok usia lanjut akan masuk dalam kategori kelompok rentan (vulnerable) yang perlu dipersiapkan kesiapannya dengan baik.

Berdasarkan tabel uji silang (tabel 10), terdapat hubungan yang signifikan antara faktor karakteristik responden yaitu pendidikan dengan 
Self Awareness responden dengan nilai $\rho$ value 0,001 ( $\rho$ value $<0,05$ ). Hasil penelitian ini sesuai dengan pendapat bahwa pendidikan merupakan faktor yang utama yang mempengaruhi kesiapsiagaan dan kesadaran masyarakat untuk berpartisipasi dalam mitigasi bencana (Pajooh, Mohammad \& Abdul, 2014). Oleh karena itu semakin berpendidikan tinggi semakin memiliki kesadaran dan memiliki kesiapsiagaan dalam bencana yang lebih baik.

Selain itu, faktor lain yang berpengaruh dalam awareness adalah pengalaman (Pajooh, Mohammad \& Abdul, 2014). Hal ini berbeda dengan hasil penelitian yang disebutkan bahwa berdasarkan tabel uji silang (tabel 11), tidak terdapat hubungan yang signifikan antara faktor karakteristik responden yaitu pengalaman dengan self awareness responden dengan nilai $\boldsymbol{\rho}$ value 0,261 ( $\rho$ value $>0,05)$. Dari hasil penelitian itu, menyebutkan bahwa faktor pengalaman tidak berdampak atau mempengaruhi awareness dari masing-masing individu dalam mitigasi bencana. Hal ini kemungkinan bisa terjadi karena pengalaman dari masing-masing individu tentang mitigasi bencana sangat minim sehingga rasa awareness yang dimiliki juga kurang baik. Hasil ini bertolak belakang dengan hasil penelitian yang dilakukan oleh Lindell and Perry (2000) dalam Pajooh, Mohammad dan Abdul (2014) yang menyatakan bahwa pengalaman dalam mitigasi bencana akan meningkatkan secara signifikan awareness dalam kesiapsiagaan bencana. Pengalaman juga akan memberikan dampak yang baik dalam pemberian informasi mengenai kemungkinan yang terjadi atau dampak bencana pada masa mendatang.

Faktor karakteristik lain berdasarkan tabel uji silang (tabel 12) di atas, tidak terdapat hubungan yang signifikan antara faktor karakteristik responden yaitu suku/ras dengan self awareness responden dengan nilai $\rho$ value $\mathbf{0 , 3 0 3}$ ( $\rho$ value $>\mathbf{0 , 0 5}$ ). Hal ini menunjukkan bahwa keberagaman suku atau ras tidak signifikan berpengaruh terhadap awareness masyarakat yang terlibat dalam mitigasi bencana. Kemungkinan hal ini disebabkan oleh pemahaman atau informasi yang luas dari masing-masing individu dalam bersikap menghadapi bencana, sehingga tidak ada perbedaan sikap awareness dari masing-masing suku yang ada. Hasil ini berbeda dengan hasil penelitiaan sebelumnya yang dinyatakan oleh Chik dan Islam (2011) disebutkan bahwa suku yang tinggal di pegunungan yang rawan bencana akan memiliki awareness yang lebih baik daripada suku yang tinggal di daerah aman atau jauh dari bencana. Sehingga jika kita lihat dari hasil penelitian sebelumnya seharusnya hasil penelitian yang dilakukan pada suku yang tinggal di sekitar gunung Bromo akan memiliki awareness yang lebih baik, akan tetapi berbeda pada kenyataannya.

Faktor karakteristik terakhir yang berpengaruh terhadap awareness adalah pendapatan. Berdasarkan tabel uji silang (tabel 13) di atas, terdapat hubungan yang signifikan antara faktor karakteristik responden yaitu pendapatan dengan self awareness responden dengan nilai $\rho$ value 0,000 ( $\rho$ value $<0,05$ ). Hal ini sesuai dengan penelitian yang dilakukan sebelumnya bahwa masyarakat dengan pendapatan yang besar akan memiliki persiapan yang lebih baik daripada masyarakat dengan pendapatan rendah. Hal ini disebabkan karena dengan pendapatan yang besar mereka dapat menggunakan dana yang dipunyai untuk upaya mitigasi bencana atau dengan kata lain mencegah terjadinya bencana dengan melakukan pembangunan yang baik. Dengan demikian resiko bencana dapat diminimalisir.

\section{KESIMPULAN DAN SARAN}

\section{Kesimpulan}

Dari beberapa faktor-faktor (jenis kelamin, usia, pendidikan, pengalaman mitigasi, suku/ras, pendapatan) yang berhubungan dengan self awareness, didapatkan bahwa faktor pendapatan yang paling mempengaruhi, dengan kekuatan hubungan $\mathrm{OR}=0,351$.

\section{Saran}

Berdasarkan hasil penelitian dan pembahasan di atas, maka diperlukan sosialisasi yang intensif oleh pemerintah daerah maupun pemerintah setempat agar masyarakat disekitar daerah rawan bencana Gunung Bromo dapat memiliki awareness yang baik. Disamping sosialisasi, pendidikan atau pelatihan yang terus-menerus kepada masyarakat juga sangat dibutuhkan agar mereka lebih terbuka (open minded) serta memiliki kemampuan dan tanggung jawab dalam kesiapan dalam menghadapi bencana, sehingga awareness atau kesadaran akan meningkat.

Perlunya penelitian lebih lanjut tentang upaya atau kegiatan mitigasi kebencanaan yang perlu disesuaikan dan ditingkatkan di daerah rawan bencana Gunung Bromo. 


\section{REFERENSI}

Austin, D. (2010). Assessing the Preparedness of Community-Based Or ganizations: Surviving the Next Disaster.

Burke, Rita V., Goodhue, Catherine J., Chokshi, Nikunj K., \& Upperman, Jeffrey S. (2011). Factors Associated with Willingness to Respond to a Disaster: A Study of Healthcare Workers in a Tertiary Setting. Prehospital and Disaster Medicine, 26 (4), p:244-250.

Chik, Z. and Islam, T. (2011). Disaster in Bangladesh and management with advanced information system, Disaster Prevention and Management, 20, p:521530.

Elazeem, Hemat Abd., Adam, Samia., \& Mohamed, Gehan. (2011). Awareness of Hospital Internal Disaster Management Plan among Health Team Members in A University Hospital. Life Science Journal, 8 (2), p:42-52.
Feldman, Joanne N., \& Tilling, Robert I. (2012). Volcanic Eruptions, Hazards, and Mitigation. In P. S. Auerbach. (Ed.), Wilderness medicine. 6 (1). p:314-332. Philadelphia: Elsevier. Journal of Volcanology and Geothermal Research p:186-194.

Mollahosseini, A. (2011). A Survey on the Role of Gender Differences in Leadership Style Selection and its Leading to Organizationall Crisi-preparedness or Crisis-proneness, 1, p:042-047.

Pajooh, E. Mohammad., Aziz, Abdul K. (2014). Investigating factors for disaster preparedness among residents of Kuala Lumpur. Journal of Natural Hazard and Earth System Science, 2 (1), p:3683-7709.

Putra, Ardia., Petpichetchian, Wongchan., \& Maneewat, Khomapak. (2011). Review: Public health nurses' roles and competencies in disaster management. Nurse Media Journal of Nursing, 1 (1), p:1-14. 